\title{
FRASEAMENTO PROSÓDICO DE ESTRUTURAS PARENTÉTICAS EM DADOS DE LEITURA NO PORTUGUÊS DO RIO DE JANEIRO
}

\author{
PROSODIC PHRASING OF PARENTHETICAL STRUCTURES \\ IN READING DATA OF BRAZILIAN PORTUGUESE FROM RIO DE JANEIRO
}

\author{
Vivian Borges Paixão | Lattes | vpaixao91@gmail.com \\ Universidade Federal do Rio de Janeiro
}

Carolina Ribeiro Serra | Lattes | carolserraufrj@gmail.com

Universidade Federal do Rio de Janeiro

Resumo: O presente artigo focaliza a realização de estruturas parentéticas no português do Brasil (PB), a partir de um ponto de vista fonológico. Partindo da literatura sobre o tema - não só no escopo da fonologia, mas também abarcando a interface com a sintaxe e os estudos do texto -, realizou-se a análise acústica e entoacional de 568 sentenças lidas por informantes cariocas do sexo feminino ( 42 sentenças x 15 falantes, excluídos 62 dados), a partir do aparato teórico-metodológico da Teoria Autossegmental e Métrica da Entoação e da Fonologia Prosódica, a fim de contribuir para a descrição da gramática entoacional do $\mathrm{PB}$, no que se refere ao fraseamento prosódico. A análise considerou a ocorrência e duração de pausas silenciosas antes e depois da parentética, além dos movimentos tonais no interior dos três sintagmas entoacionais (IPs) ideais que constituem cada enunciado. Confirmaram-se duas das hipóteses iniciais: (i) a de que a estrutura parentética é realizada, no PB, como um IP independente e (ii) a de que o fraseamento prosódico da parentética é sensível ao tamanho do primeiro IP do enunciado. Os resultados revelaram diferenças interessantes em relação àqueles obtidos por outros pesquisadores para o português europeu (PE): no $\mathrm{PB}$, os dados indicam serem mais frequentes as pausas no final da parentética e os contornos descendentes no primeiro e no segundo IPs, enquanto no PE predominam as pausas no início da parentética e os contornos ascendentes.

Palavras-chave: Parentéticas; Fraseamento prosódico; Entoação; Pausa; Português do Brasil. 
Abstract: This article focuses on the realization of parenthetical structures in Brazilian Portuguese (BP), from a phonological point of view. We departed from the literature review, not only in the scope of phonology, but also in the interface with syntax and text studies, and we did acoustic and intonational analysis of 568 sentences read out (42 sentences x 15 speakers, excluding 62 data), from the theoretical and methodological framework of the Autosegmental-Metrical Theory of Entonation and of the Prosodic Phonology, in order to contribute to the description of the intonational grammar of BP, with regard to prosodic phrasing. The analysis considered the occurrence and duration of silent pauses before and after the parentheticals, as well as the tonal movements within the three ideal intonational phrases (IPs) that constitute each utterance. Two of the initial hypotheses were confirmed: (i) that the parenthetic structure is performed in BP as an independent IP and (ii) that the prosodic phrasing of the parenthetical is sensitive to the size of the first IP of the utterance. The results revealed interesting differences in relation to those obtained by other researchers for European Portuguese (EP): in BP, our data indicate that pauses on the left of the parenthetical are more frequent than pauses on its right. Also, we found out that the descending contours in the first and second IPs are predominant. In EP, differently, literature indicates that pauses at the beginning of parentheticals predominate, as well as ascending contours in the first and second IPs.

Keywords: Parentheticals; Prosodic phrasing; Intonation; Pause; Brazilian Portuguese.

\section{Apresentação do objeto de estudo}

Este artigo tem como objetivo investigar de que forma se dá o fraseamento prosódico de estruturas parentéticas no português do Brasil (PB) - fala carioca, em dados de leitura de frases, a partir de uma abordagem fonológica. A hipótese testada é a de que há um fraseamento default dessas estruturas, no PB, no sentido de constituírem um sintagma entoacional (IP) independente dos elementos à esquerda e à direita da parentética; e de que o tamanho do IP à esquerda é um fator importante para essa delimitação: quanto maior o elemento à esquerda, mais robustas as fronteiras prosódicas entre esse elemento e a parentética.

O primeiro passo no sentido de caracterizar prosodicamente as parentéticas consiste em conceituar essas estruturas, ou seja, apresentar o termo usado para definir nosso objeto de estudo. Para tanto, é fundamental estabelecer diálogo com trabalhos na área da linguística textual que se debruçam sobre o mesmo tema. A própria denominação "pa- 
rentéticas" remete a uma perspectiva textual-discursiva, e a maior parte da literatura que busca caracterizar tais estruturas, em especial no $\mathrm{PB}$, o faz desse ponto de vista.

Os trabalhos de Nicole Dehé são, possivelmente, aqueles de maior relevância no cenário internacional no que tange ao tópico das inserções parentéticas. Em seu livro Parentheticals in spoken English: the syntax-prosody relation (DEHÉ, 2014), a autora faz uma exaustiva revisão da bibliografia sobre o tema, apresentando um levantamento das várias definições oferecidas pela literatura. Busca, ainda, a interseção entre as ideias apresentadas por cada um dos autores estudados, afirmando, sinteticamente, que todas as definições apontadas por eles

têm em comum o fato de que uma parentética é considerada uma entidade linguística que é linearmente integrada em outra estrutura linguística, mas não é relacionada ao material linguístico circundante de uma forma ou de outra, i. e., em termos de estrutura sintática, significado semântico e/ou entoação. (DEHÉ, 2014, p. 1, tradução nossa). ${ }^{1}$

Essa definição constitui um denominador comum entre aquelas propostas por outros autores, como Burton-Roberts (2006, p. 179), que afirma que uma parentética (P) é 'uma expressão sobre a qual se pode afirmar que, sendo, em certo sentido, 'hospedada' por outra expressão $(H)$, não traz qualquer contribuição para a estrutura de $\mathrm{H}^{\text {”2 }}$, ou seja, P e H são estruturalmente não relacionadas.

No âmbito dos estudos do discurso, inclusive do PB, há alguns trabalhos que tratam das construções parentéticas, com destaque para os de Jubran (1996a, 1996b, 1999, 2002, 2006) e Jubran et al. (1993, 1996), que integram os estudos do grupo de Organização Textual-Interativa do Projeto da Gramática do Português Falado. Nessa perspectiva, de acordo com Jubran (1996a), os parênteses têm sido vistos como frases independentes inseridas em outras frases, com interrupção da estrutura sintática e sem conexão formal nitidamente estabelecida.

No tocante à semântica, no entanto, a parentetização é entendida como "um fenômeno de articulação de informações no discurso oral, e não como um fenômeno que provoca descontinuidade na progressão temática do discurso” (MINCOFF, 2008, p. 4). Essas construções, de acordo com Jubran (2006), subdividem-se em (i) estruturas com estatuto tópico, quando o conteúdo da parentética constitui uma explicação ou escla-

\footnotetext{
${ }^{1}$ No original: "... all of which have in common that a parenthetical is considered a linguistic entity which is linearly integrated in another linguistic structure but is unrelated to the surrounding linguistic material in one way or another, i.e. in terms of syntactic structure, semantic meaning and/or intonation."

2 No original: "an expression of which it can be argued that, while in some sense 'hosted' by another expression $(\mathrm{H})$, P makes no contribution to the structure of $\mathrm{H}^{\prime}$
} 
recimento, com relação íntima com o tema em discussão; e (ii) estruturas sem estatuto tópico, tidas como propriamente parentéticas, quando há ruptura do tópico e posterior retomada.

A autora ressalta que os parênteses podem exercer diversas funções textual-interativas, e classifica-os segundo quatro tipos: (i) parênteses focalizadores da elaboração tópica do texto, (ii) parênteses com foco no locutor, (iii) parênteses com foco no interlocutor e (iv) parênteses focalizadores do ato comunicativo. Esses quatro tipos de inserções parentéticas - que se subdividem segundo suas funções específicas - distribuem-se ao longo de um continuum de graus de desvio do tópico discursivo, sendo o tipo (i) aquele que menos se desvia e o tipo (iv) aquele que mais se desvia do tópico.

É importante ressaltar que, embora os trabalhos de Jubran (1996a, 1996b, 1999, 2006) e Jubran et al. (1993, 1996) façam referência a fatos prosódicos como marcas formais delimitadoras dos parênteses, essa observação não se fundamenta em análises prosódicas mais acuradas, permanecendo em um nível um tanto impressionístico. De fato, os estudos sobre as parentéticas no $\mathrm{PB}$ restringem-se quase exclusivamente ao campo da linguística textual, havendo pouquíssima pesquisa sobre o tema que aborde a caracterização prosódica do fenômeno.

Na sequência da apresentação do objeto de estudo realizada nesta primeira seção, este artigo conta com a seção 2 , em que se faz uma caracterização prosódica das parentéticas a partir de revisão da literatura. Na seção 3, apresenta-se a fundamentação teórica e metodológica empregada na pesquisa. Em seguida, na seção 4, detalham-se os materiais e procedimentos utilizados, e na seção 5 são apresentados os resultados da análise de dados e discussão desses resultados. Por fim, na seção 6, são feitas algumas considerações finais, e propostas ideias para o aprofundamento da pesquisa sobre a prosódia das parentéticas no PB.

\section{Caracterização prosódica das parentéticas: alguma literatura}

Sobre a caracterização prosódica das parentéticas, destaca-se a dissertação de Mestrado de Tenani (1995), que utiliza dados de fala espontânea do Projeto da Norma Urbana Culta (NURC) e faz uma análise auditiva das marcas prosódicas de estruturas parentéticas, levando em conta parâmetros de velocidade de fala, pausa, tessitura, entonação e volume de voz, além de correlacioná-las com as marcas sintáticas características de tais estruturas. $\mathrm{O}$ estudo é pioneiro, na medida em que descreve um fenômeno prosódico nunca antes tratado, e o faz de um ponto de vista ainda ligado à linguística textual, utilizando-se da fonética perceptiva como ferramenta de análise. 
Mais tarde, em sua tese de doutoramento (TENANI, 2002), a autora estuda os domínios prosódicos no PB, comparando dados de fala espontânea e leitura. Acerca das estruturas parentéticas, conclui que, na modalidade espontânea, não são obrigatoriamente delimitadas por pausa, enquanto, na leitura, há uma pausa no final da parentética que indica a fronteira de uma frase entoacional (IP). Os resultados de Serra (2009) para testes de percepção com dados de fala espontânea e leitura do PB corroboram essa afirmação, uma vez que as rupturas associadas a estruturas parentéticas estão entre aquelas com maior índice de reconhecimento.

Já para o português europeu (PE), os estudos das parentéticas a partir de um ponto de vista fonológico se encontram em estágio mais avançado. Frota $(2000,2014)$ estuda a entoação da variedade standard do PE, falada em Lisboa, em dados de leitura, utilizando as linhas teóricas da AM e da Hierarquia Prosódica e analisa, inclusive, a ocorrência de parentéticas. Nos trabalhos de Frota, essas estruturas são descritas, em termos prosódicos, como constituindo um IP próprio, independente do restante do enunciado, e cercado por dois tons de fronteira, um inicial e um final.

Cruz (2013), em sua tese de doutoramento, estuda a variação prosódica em duas variedades centro-meridionais do PE, abordando também as parentéticas. A autora também considera que as estruturas formam IPs independentes, com fronteiras marcadas por fenômenos segmentais, temporais e entoacionais característicos desses constituintes.

A dissertação de Mestrado de Barros (2014) se debruça especificamente sobre a questão das parentéticas, a partir de uma perspectiva teórica que conjuga a Teoria Autossegmental e Métrica e os princípios da Hierarquia Prosódica, na mesma linha dos trabalhos de Cruz (2013) e de Frota (2000, 2014). Inserido no âmbito do projeto InAPoP (Interactive Atlas of the Prosody of Portuguese), o trabalho analisa o fraseamento prosódico e a entoação em enunciados com construções parentéticas e tópicos em duas variedades do PE. A autora verifica uma tendência de as parentéticas formarem IPs separados e aponta, ainda, maior concentração de pausas e valores mais altos de gama de variação de F0 (ou seja, a diferença entre o valor mais alto e o valor mais baixo na curva de F0 da palavra nuclear do IP) na fronteira que precede a parentética.

\section{Fundamentação teórica e metodológica}

Como fundamentação teórico-metodológica, foram utilizados os pressupostos da teoria Autossegmental e Métrica da Entoação (AM) (PIERREHUMBERT, 1980; LADD, 2008; FROTA et al., 2015, entre outros), a partir da qual se fez a análise e nota- 
ção entoacional dos enunciados. Recorreu-se também ao arcabouço teórico da Fonologia Prosódica, que propõe a segmentação do fluxo da fala em domínios prosódicos gramaticalmente estruturados, na linha dos trabalhos de Selkirk (1984, 1986), Nespor e Vogel (2007 [1986]), entre outros. Ademais, a metodologia inclui os procedimentos da Fonética Acústica Experimental (BARBOSA; MADUREIRA, 2015), aplicados à análise dos dados no programa computacional Praat (BOERSMA; WEENINK, 1992-2015).

Emprega-se, portanto, uma visão integrada, em que a entoação atua como uma das pistas que sinalizam a existência de uma estrutura prosódica (FROTA, 2000). Na abordagem adotada, pressupõe-se uma hierarquia de proeminências acentuais - por exemplo, no nível da palavra, uma sílaba só pode ser considerada "forte" relativamente à outra, que é "fraca”. Assim, os aspectos básicos da entoação, isto é, as relações de proeminência acentual que caracterizam os contornos entoacionais estão, assim como os fenômenos de juntura e estabelecimento de fronteiras, evidenciando a existência da estrutura prosódica.

\subsection{Teoria Autossegmental e Métrica da Entoação}

O modelo autossegmental e métrico se propõe a analisar a estrutura entoacional das línguas por meio de eventos tonais, ou seja, movimentos estabelecidos entre os diferentes níveis de altura tonal que se verificam ao longo de um enunciado. Busca determinar, a partir da relação entre esses níveis, o que tem papel fonológico nas línguas - fazendo parte, portanto, da gramática entoacional das línguas naturais - e o que consiste em variação no nível fonético, relacionando-se a um mesmo padrão frásico. $\mathrm{Na} \mathrm{AM}$, os tons são classificados em níveis de altura: alto ( $\mathrm{H}$, de high) e baixo (L, de low), e configuram, dessa forma, elementos contrastivos que se organizam em sequência e formam os contornos melódicos, ou contornos de F0. Deve-se salientar que, de acordo com Ladd (2008 [1996]), os níveis H e L são abstrações fonológicas, não havendo, necessariamente, correspondência direta entre os níveis de altura e valores absolutos de F0.

De acordo com o aparato metodológico da AM, atribuem-se marcas notacionais específicas aos tons relacionados às sílabas portadoras de acento lexical e aos tons relacionados a fronteiras de constituintes prosódicos. Os tons associados ao acento lexical são assinalados com um asterisco $\left(^{*}\right)$ após a letra $\mathrm{H}$ ou L. Quanto aos tons relacionados às fronteiras de constituintes prosódicos, subdividem-se em dois tipos: os chamados tons de fronteira, associados a limite de sintagma entoacional (IP), são assinalados com um símbolo de porcentagem (\%); e os acentos frasais, associados a limites de constituintes menores, são indicados por um travessão (-) depois do H ou L. Outros símbolos notacionais que podem acompanhar os tons $\mathrm{H}$ e L são o ponto de exclamação (!), represen- 
tando o processo de downstep - quando um tom $\mathrm{H}$ é relativamente mais baixo que o tom $\mathrm{H}$ anterior - ou o ponto de exclamação invertido $(i)$, representando o processo de upstep - um tom $\mathrm{H}$ relativamente mais alto do que o tom $\mathrm{H}$ anterior.

A organização fonológica da entoação, segundo o modelo $A M$, se relaciona com a estrutura prosódica das línguas (BECKMAN; PIERREHUMBERT, 1986; LADD, 2008, entre outros). Os eventos tonais associados à fronteira de constituinte prosódico são de fundamental importância para o fraseamento prosódico - a divisão do fluxo da fala em unidades entoacionais -, uma vez que funcionam como índices de ruptura melódica, associados ou não a outras pistas como a ocorrência de pausa, o alongamento pré-fronteira, etc. (SERRA, 2009, 2016; FERNANDES-SVARTMAN et al., a sair).

\subsection{Fonologia Prosódica}

A Fonologia Prosódica postula que o fluxo da fala é dividido em unidades fonológicas hierarquicamente organizadas, fato que se reflete, nas línguas, em processos fonológicos tanto no nível segmental quanto no suprassegmental. A Hierarquia Prosódica é composta tradicionalmente por sete domínios, distribuídos em ordem crescente, a saber: sílaba $(\sigma)$, pé métrico $(\Sigma)$, palavra prosódica $(\omega)$, grupo clítico $(C)$, sintagma fonológico, $(\varphi)$, sintagma entoacional (IP) e enunciado fonológico (U). Essa hierarquia costuma ser representada na forma de diagrama arbóreo (cf. Figura 1), que remete à filiação dessa teoria à Fonologia Gerativa Clássica (CHOMSKY; HALLE, 1968).

Figura 1. Hierarquia dos constituintes prosódicos

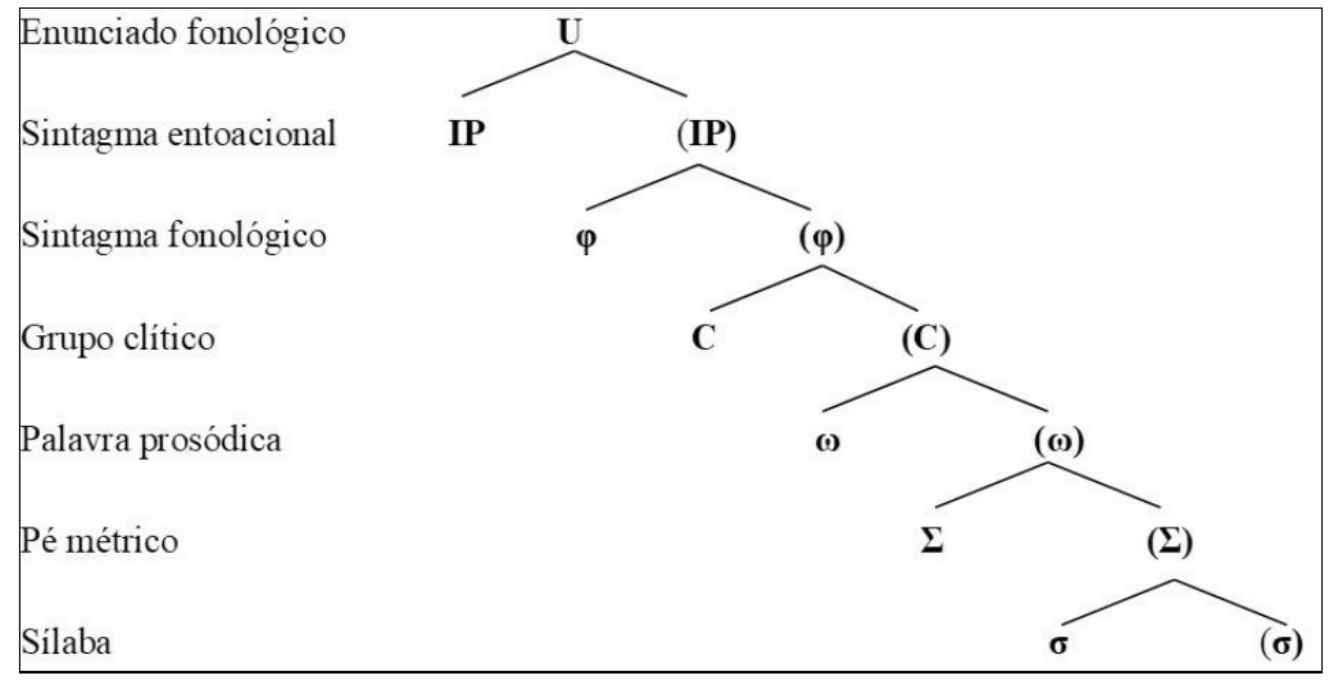

Fonte: Caldas (2018, p. 32) 
Nesta pesquisa, destaca-se o papel do domínio prosódico do sintagma entoacional (IP), que compreende todas as sequências de $\varphi s$ adjacentes numa oração matriz ou todos os $\varphi s$ não estruturalmente ligados à oração, como é o caso das parentéticas. Do ponto de vista entoacional/prosódico, este domínio se caracteriza no PB: (i) pela presença de um acento nuclear e de um tom de fronteira no seu limite direito; (ii) pela ocorrência de um acento pré-nuclear em sua primeira palavra prosódica; e (iii) pela inserção de pausas delimitando-o e pela alta densidade de acentos tonais nas palavras prosódicas que o constituem internamente (MORAES, 2008; FROTA; VIGÁRIO, 2000; TENANI, 2002; FERNANDES, 2007; SERRA, 2009, 2016; SILVESTRE, 2012). O domínio da palavra prosódica $(\mathrm{Pw})$ também recebe especial atenção, uma vez que o número de Pws à esquerda da parentética consiste em uma de nossas variáveis. $\mathrm{O}$ algoritmo de formação da palavra prosódica prevê que esse constituinte tem um único acento lexical (o grupo de palavra prosódica tem um único elemento proeminente). Todo elemento com acento de palavra tem de estar incluído numa palavra prosódica (VIGÁRIO, 2010).

De acordo com os princípios da Fonologia Prosódica, a estrutura fonológica está em relação com outras estruturas da gramática, principalmente com a sintática - a própria forma como o modelo assume a constituição da estrutura fonológica remete às regras de constituição sintática. A partir dessa relação, pode-se prever uma segmentação ideal do contínuo de fala em domínios prosódicos, que pode ou não se confirmar pela análise de dados concretos. É importante ressaltar, porém, que essa interação não se dá de maneira isomórfica, havendo intenso debate acerca de que tipo de informação pode ou não ser acessado no mapeamento sintaxe-fonologia (SELKIRK, 1984, 1986; NESPOR; VOGEL, 1986).

\section{Materiais e procedimentos}

Os dados analisados nesta pesquisa são de fala controlada, e levou-se em consideração, para a constituição da amostra, a ideia de que as estruturas parentéticas classificam-se em vários subtipos, a partir de sua função textual-interativa (JUBRAN, 2006, entre outros trabalhos). Assim, os dados analisados totalizam 14 trios de enunciados, de tamanho variável em número de sílabas e de palavras prosódicas $(2 \mathrm{Pw}, 3 \mathrm{Pw}$ ou $4 \mathrm{Pw})$, os quais possuem inserções parentéticas classificadas em dois tipos; sete dos trios de enunciados contêm parentéticas do tipo oracional, que consistem, em termos semântico-discursivos, em um comentário geral sobre a sentença (cf. exemplo 1); nos outros sete trios, as inserções são do tipo não oracional e consistem em um aposto/comentário relativo à primeira parte da oração matriz (cf. exemplo 2). 
Para a elaboração dos enunciados utilizados no teste de leitura, nas fronteiras entre a parentética e as partes da oração matriz que a ladeavam, foram evitados contextos segmentais que propiciassem a aplicação de fenômenos de sândi externo. Essa decisão metodológica visava a minimizar a interação entre texto e melodia nas fronteiras dos constituintes prosódicos, na medida em que os processos de junção segmental podem atuar para a reorganização da cadeia melódica (FROTA et al., 2015), e o nosso objetivo principal era observar as estratégias de fraseamento prosódico relativamente ao tamanho do primeiro constituinte da oração matriz.

(1) aquelas mulheres | por mais que elas neguem | precisam de ajuda aquelas pobres mulheres | por mais que elas neguem | precisam de ajuda aquelas pobres mulheres cansadas | por mais que elas neguem | precisam de ajuda

(2) o irmão da vizinha | sujeito muito honesto | comprou um carro o irmão caçula da vizinha | sujeito muito honesto | comprou um carro o irmão caçula da vizinha fofoqueira | sujeito muito honesto | comprou um carro

Os enunciados fazem parte de um corpus maior de fala controlada, que serve de base para diversos estudos no âmbito do projeto de pesquisa Fraseamento prosódico, variação e a interface prosódia-sintaxe no português do Brasil (PPGLEV-UFRJ). O teste de leitura foi realizado por 15 falantes cariocas, todas do sexo feminino, estudantes de pós-graduação da UFRJ e com idades entre 22 e 30 anos. As informantes leram, cada uma, 127 frases, perfazendo um total de 1.860 dados produzidos, incluindo, além das estruturas com inserções parentéticas, estruturas com orações justapostas, com o sequenciador "aí", com o marcador discursivo "né”, sentenças com /R/ em vários contextos e orações adverbiais desgarradas. Desse total, foram computados 630 dados com parentéticas, 62 dos quais foram descartados, por não apresentarem condições satisfatórias para a análise acústica/entoacional. Contamos, portanto, com 568 dados analisados, de fato, referentes às parentéticas, objeto de estudo desta pesquisa. Esses dados de parentéticas não continham qualquer tipo de sinal de pontuação que pudesse influenciar a leitura das falantes; elas puderam, entretanto, fazer a leitura silenciosa das frases antes de produzi-las.

Devido ao volume do corpus, cada falante realizou o teste de leitura em duas sessões, em dias diferentes. As frases eram apresentadas na tela do computador de forma randomizada (mesclando-se os tipos frásicos investigados), e a falante dispunha do tempo que 
desejasse para lê-los em voz alta. O programa computacional utilizado para realização do teste foi o Psyscope $\mathrm{X}^{3}$, e a captação de som foi feita com um gravador Sony modelo PCM-D50, com capacidade de 96KHz/24bit.

Partindo de uma segmentação ideal que considera a parentética um sintagma entoacional (IP) independente (NESPOR; VOGEL, 2007 [1986]), foram observadas pistas acústicas relacionadas à presença de fronteiras prosódicas nos limites das inserções parentéticas. A análise acústica levou em conta, portanto, 1) a presença e duração de pausas silenciosas antes e depois da parentética; e 2), em cada um dos três IPs dos enunciados, a configuração da curva de F0, de acordo com os princípios da teoria AM. A partir da observação da curva de F0, realizou-se a notação entoacional dos contornos nucleares de cada um dos IPs, ou seja, a notação do movimento tonal sobre a última palavra prosódica de cada IP.

Os resultados da análise acústica e entoacional foram submetidos a tratamento estatístico através do programa $\mathrm{R}$ ( $\mathrm{R}$ Core Team, 2016), para observar a distribuição dos fatores e testar a significância estatística dos resultados ${ }^{4}$.

\section{Análise dos dados e discussão dos resultados}

A ocorrência de pausas silenciosas antes e depois da parentética é, possivelmente, a pista acústica mais comumente associada a este tipo de estrutura no que concerne à prosódia (JUBRAN, 2002; SERRA, 2009). Essa ideia, que aponta para a tendência ao fraseamento das parentéticas em um IP independente do restante do enunciado, não encontra confirmação nos nossos dados: na leitura, não há, necessariamente, uma pausa silenciosa delimitando o IP da parentética, embora a ocorrência de pausa aumente conforme vai aumentando o tamanho do primeiro IP, em termos de número de palavras prosódicas. Os dados também não revelaram relação entre a ocorrência e duração de pausa ou o tipo de contorno entoacional e o tipo de parentética (oracional $x$ não oracional).

É interessante, nesse ponto, estabelecer contraste com os resultados de Barros (2014) para o PE: a autora afirma que, naquela variedade do português, a pausa ocorre mais frequentemente na primeira fronteira delimitadora da parentética. Nos nossos dados, os percentuais gerais de ocorrência de pausa são muito próximos na primeira e na segunda fronteiras que ladeiam a parentética, sendo a segunda fronteira (entre a parentética e o IP à direita), inclusive, ligeiramente mais demarcada por pausa do que a primeira (cf. Tabela 1).

\footnotetext{
${ }_{3}$ Agradecemos ao Prof. Marcus Maia e ao Laboratório de Psicolinguística Experimental (LAPEX/UFRJ) pela valiosa contribuição na montagem do experimento e pelo empréstimo dos equipamentos.

${ }^{4}$ Agradecemos à Juliane Venturelli, da UFMG, pelo auxílio na escolha e execução dos testes estatísticos.
} 
Tabela 1. Percentual de ocorrência e média de duração das pausas nas duas fronteiras da parentética por número de palavras prosódicas no primeiro IP

\begin{tabular}{|c|c|c|c|c|}
\hline \multirow{2}{*}{$\begin{array}{c}\text { Tamanho do 1o } \\
\text { IP }\end{array}$} & \multicolumn{2}{|c|}{$\mathbf{1}^{\text {a } \text { fronteira }}$} & \multicolumn{2}{c|}{ 2 fronteira $^{\text {a }}$} \\
\cline { 2 - 5 } & Dur. pausa & \% oco.pausa & Dur. pausa & \% oco.pausa \\
\hline 2pw & $0,167 \mathrm{~s}$ & $27,8 \%$ & $0,164 \mathrm{~s}$ & $36,7 \%$ \\
\hline 3pw & $0,176 \mathrm{~s}$ & $33,5 \%$ & $0,153 \mathrm{~s}$ & $40,8 \%$ \\
\hline 4pw & $0,190 \mathrm{~s}$ & $44,4 \%$ & $0,166 \mathrm{~s}$ & $40,7 \%$ \\
\hline Geral & $0,179 \mathrm{~s}$ & $34,8 \%$ & $0,160 \mathrm{~s}$ & $39,4 \%$ \\
\hline
\end{tabular}

Fonte: As autoras (2018).

Na Figura 2, por exemplo, verifica-se um constituinte com quatro Pw no primeiro IP, em que ocorrem pausas silenciosas em ambas as fronteiras: antes e depois da parentética.

Figura 2. Enunciado 07C, informante BA

[A filha adolescente da Dona Julieta $]_{I P}$ [disseram as más línguas $]_{I P}$ [saiu com o Carlos $]_{I P}$.

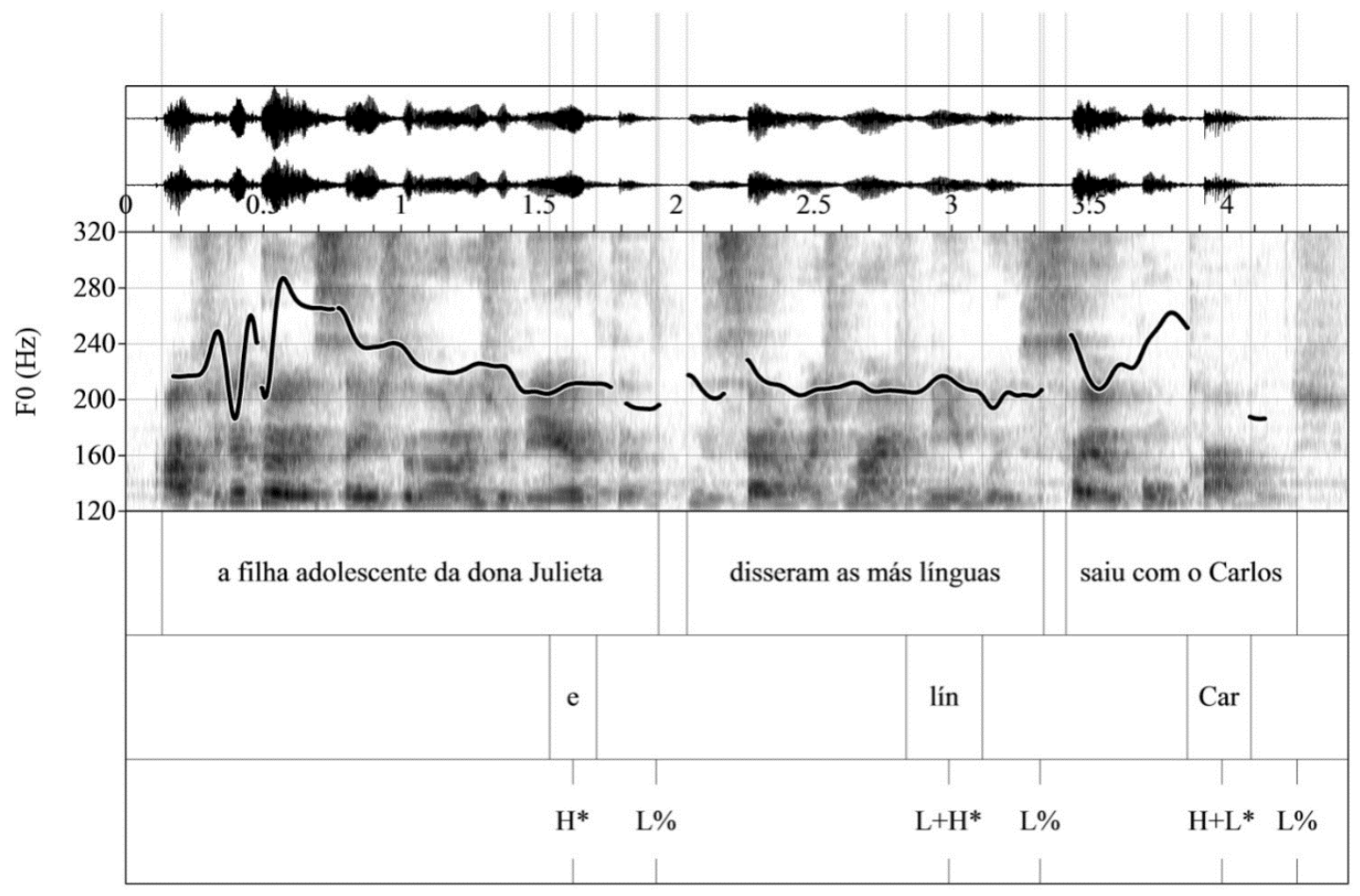

Fonte: As autoras (2018). 
No tocante à ocorrência e duração de pausas silenciosas, o teste estatístico revelou que o tamanho do IP à esquerda da parentética mostrou-se relevante para a demarcação de fronteiras duracionais. Na Tabela 1, é possível verificar que os valores referentes à duração e ao percentual de ocorrência de pausas na primeira fronteira crescem gradativamente conforme aumenta o número de palavras prosódicas no primeiro IP do enunciado. Em outras palavras, pode-se afirmar que, quanto maior o primeiro IP, maior a frequência e duração das pausas silenciosas na primeira fronteira.

Gráfico 1. Boxplot de distribuição da duração da primeira pausa pelo número de Pw no primeiro IP do enunciado

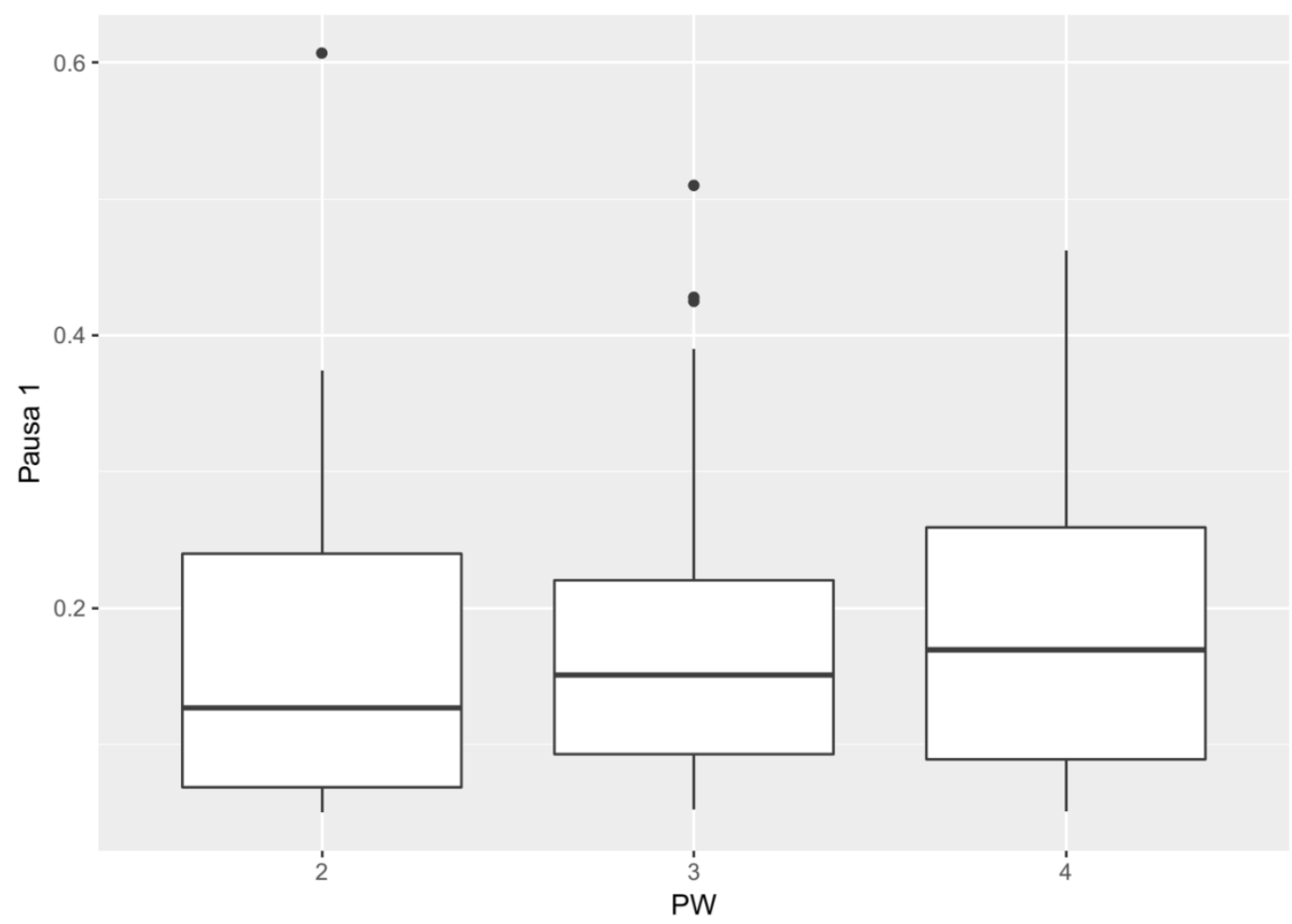

Fonte: As autoras (2018).

No Gráfico 1, acima, pode-se visualizar a distribuição das pausas da primeira fronteira: a linha que divide cada uma das caixas representa a mediana, cujo valor aumenta conforme aumenta o tamanho do primeiro IP.

A fim de verificar se os resultados eram estatisticamente significativos, realizaram-se os testes estatísticos (i) Chi Quadrado, para testar a associação entre ocorrência de pausa e número de Pw no primeiro IP e (ii) Anova, para testar a igualdade das médias de pausa nos diferentes tamanhos de enunciado. O teste Chi Quadrado revelou evidências 
de associação entre quantidade de Pw e ocorrência da primeira pausa ( $\mathrm{p}$-valor = 0,0110); mas não entre quantidade de $\mathrm{Pw}$ e ocorrência da segunda pausa ( $\mathrm{p}$-valor $=0,6956)$. Já o teste Anova não revelou diferença significativa entre as médias de duração da primeira ( $\mathrm{p}$-valor $=0,572)$ e da segunda pausa $(\mathrm{p}$-valor $=0,699)$.

No que se refere à análise entoacional dos contornos nucleares, mais uma vez, nossos dados mostraram, para o $\mathrm{PB}$, uma tendência oposta àquela verificada por Barros (2014) para o PE. A autora encontrou predomínio de tons de fronteira altos e movimentos ascendentes nos dois primeiros IPs dos enunciados. Nos nossos dados, diferentemente, predominam os tons de fronteira baixos e movimentos descendentes ou circunflexos, também nos dois primeiros IPs (cf. Figura 3). O terceiro IP do enunciado, tanto no PE como no PB, caracteriza-se quase categoricamente por um contorno descendente.

Figura 3. Enunciado 01A, informante AA

[Aquelas mulheres $]_{I P}[\text { por mais que elas neguem }]_{I P}[\text { precisam de ajuda }]_{I P}$.

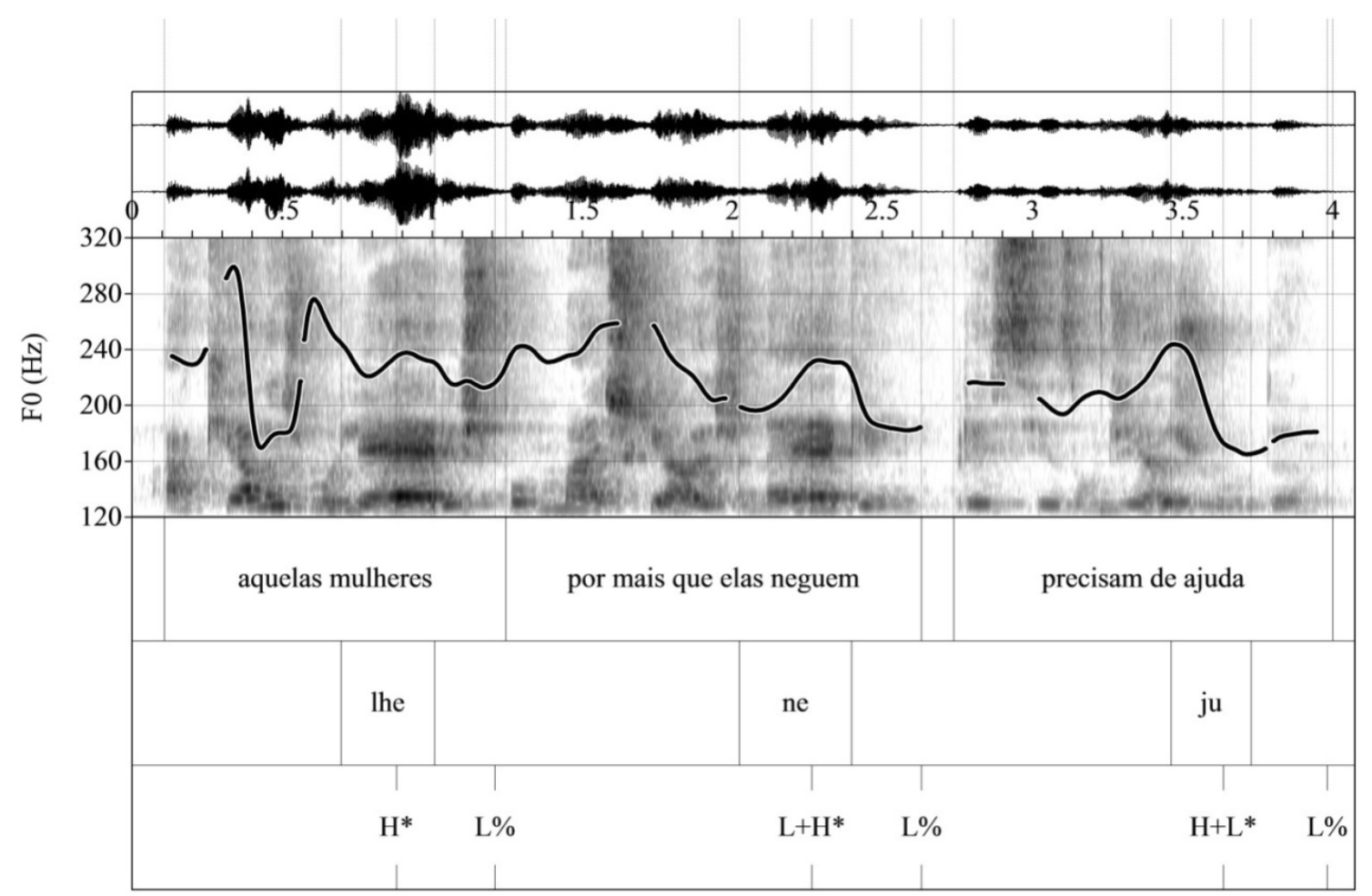

Fonte: As autoras (2018).

Observou-se grande variedade de acentos tonais nucleares, tanto no primeiro IP quanto no IP da parentética (cf. Quadro 1 e Tabela 2). Realizou-se, no programa R, o cruzamento das variáveis (i) tipo de parentética, (ii) movimento tonal no primeiro IP e (iii) movimento tonal no segundo IP. No entanto, não foi possível verificar qualquer 
relação entre o tipo de contorno nuclear realizado e o tamanho do primeiro IP ou o tipo de parentética.

Quadro 1. Contornos nucleares encontrados nos dados

\begin{tabular}{|c|c|}
\hline Contorno & Etiqueta \\
\hline $\mathbf{H}^{*} \mathbf{H} \%$ & Planificado Alto \\
\hline $\mathbf{L}^{*} \mathbf{L} \%$ & Planificado Baixo \\
\hline $\mathbf{L}^{*} \mathbf{H} \%$ & Ascendente \\
\hline $\mathbf{L}^{*}+\mathbf{H H} \%$ & Ascendente \\
\hline $\mathbf{L}+\mathbf{H}^{*} \mathbf{H} \%$ & Ascendente \\
\hline $\mathbf{L}^{*}+\mathbf{L H} \%$ & Ascendente \\
\hline$H^{*} \mathbf{L} \%$ & Descendente \\
\hline $\mathbf{H}^{*} \mathbf{H} \mathbf{L} \%$ & Descendente \\
\hline $\mathbf{H}^{*}+\mathbf{L L} \%$ & Descendente \\
\hline $\mathbf{H}+\mathbf{L}^{*} \mathbf{L} \%$ & Descendente \\
\hline $\mathbf{H}^{*}+\mathbf{L H} \%$ & Descendente-Ascendente \\
\hline $\mathbf{H}+\mathbf{L}^{*} \mathbf{H} \%$ & Descendente-Ascendente \\
\hline $\mathbf{H}+\mathbf{L}^{*} \mathbf{L H} \%$ & Descendente-Ascendente \\
\hline H* $^{*} \mathbf{L L H} \%$ & Descendente-Ascendente \\
\hline $\mathbf{L}^{*}+\mathbf{H L} \%$ & Circunflexo \\
\hline $\mathbf{L}+\mathbf{H}^{*} \mathbf{L} \%$ & Circunflexo \\
\hline $\mathbf{L}^{*}+\mathbf{H H L} \%$ & Circunflexo \\
\hline $\mathbf{L}+\mathbf{H}^{*} \mathbf{H L} \%$ & Circunflexo \\
\hline
\end{tabular}

Fonte: As autoras (2018).

Tabela 2. Distribuição percentual geral dos contornos nucleares nos três IPs dos enunciados

\begin{tabular}{|c|c|c|c|c|c|c|}
\hline Contorno & Oco. $1^{\circ}$ IP & $\% 10$ IP & Oco. $2^{\circ}$ IP & $\% 2^{\circ}$ IP & Oco. $3^{\circ}$ IP & $\% 3^{\circ}$ IP \\
\hline Ascendente & 114 & $20,1 \%$ & 129 & $22,8 \%$ & 1 & $0,2 \%$ \\
\hline Circunflexo & 170 & $30 \%$ & 163 & $28,7 \%$ & 1 & $0,2 \%$ \\
\hline Desc.-Asc. & 77 & $13,6 \%$ & 73 & $12,9 \%$ & 1 & $0,2 \%$ \\
\hline Descendente & 176 & $31,1 \%$ & 165 & $29,1 \%$ & 561 & $98,8 \%$ \\
\hline Plano Alto & 5 & $0,9 \%$ & 10 & $1,7 \%$ & 0 & $0 \%$ \\
\hline Plano Baixo & 16 & $2,8 \%$ & 20 & $3,5 \%$ & 4 & $0,7 \%$ \\
\hline $\mathbf{N} / \mathbf{A}$ & 9 & $1,5 \%$ & 7 & $1,3 \%$ & 0 & $0 \%$ \\
\hline Total Geral & 568 & $100 \%$ & 568 & $100 \%$ & 568 & $100 \%$ \\
\hline
\end{tabular}

Fonte: As autoras (2018). 
Analisando a Tabela 2, a primeira observação a se fazer é a de que, em termos de ocorrência de fronteira melódica, a parentética funciona como um IP independente, sendo delimitada por tons de fronteira tanto à sua direita $(98,7 \%)$ quanto à sua esquerda (98,5\%) (neste último caso, o tom de fronteira está associado ao final do IP anterior), mesmo com frequência relativamente baixa de pausas nas fronteiras. De 100\% dos dados para cada contexto, somente em 1,5\% (9) não ocorreu fronteira melódica entre o primeiro IP e a parentética, e somente em $1,3 \%$ dos dados (7) não ocorreu um tom de fronteira no IP da parentética.

Esses resultados demonstram 1) que nem sempre a pausa silenciosa irá demarcar as estruturas parentéticas na fala lida e 2) que o mapeamento sintaxe-prosódia é robusto, no que se refere à delimitação prosódica das parentéticas. De acordo com o algoritmo de formação do sintagma entoacional, todas as sequências de sintagmas fonológicos $(\varphi)$ em uma oração raiz formam um IP e toda sequência não estruturalmente anexada à oração raiz (NESPOR; VOGEL, 2007 [1996]) deve constituir um IP próprio; é o caso de estruturas parentéticas, vocativos, tag questions etc. Embora a formação de IP esteja sujeita a condições de tamanho prosódico, no sentido de sintagmas longos (em número de sílabas e de palavras prosódicas) comumente serem divididos e sintagmas pequenos poderem formar um único IP com um IP adjacente, o que leva à formação de sintagmas com tamanhos equilibrados (FROTA, 2000; SERRA, 2009), em nossos dados, mesmo o menor IP das estruturas analisadas por nós, aquele que contém $2 \mathrm{Pw}$, não foi reestruturado com o IP seguinte. Parece-nos que o IP parentético, portando conteúdo semântico-discursivo que se desvia do tópico discursivo mais geral da sentença, necessita sempre estar marcado prosodicamente, confirmando o que indicam os estudos sobre os parênteses na perspectiva textual-discursiva, e independentemente de sua constituição sintática interna ser oracional ou não oracional.

Em termos de configuração melódica, destacou-se, na amostra, a ocorrência dos contornos circunflexo e descendente, ao final tanto do primeiro quanto do segundo IP: em torno de $30 \%$ de cada tipo em ambos os contextos. No que se refere ao IP final, confirma-se, mais uma vez, a preferência pelo movimento melódico descendente (98,8\%), típico das declarativas neutras no português (Tabela 2). A Figura 4, a seguir, ilustra a ocorrência de contornos descendentes nos dois primeiros IPs, e a Figura 5 é um exemplo de ocorrência de contornos circunflexos. 
Figura 4. Enunciado 04A, informante AA

[A garota francesa $]_{I P}[\text { pudemos notar na festa }]_{I P}[\text { dançava bastante }]_{I P}$

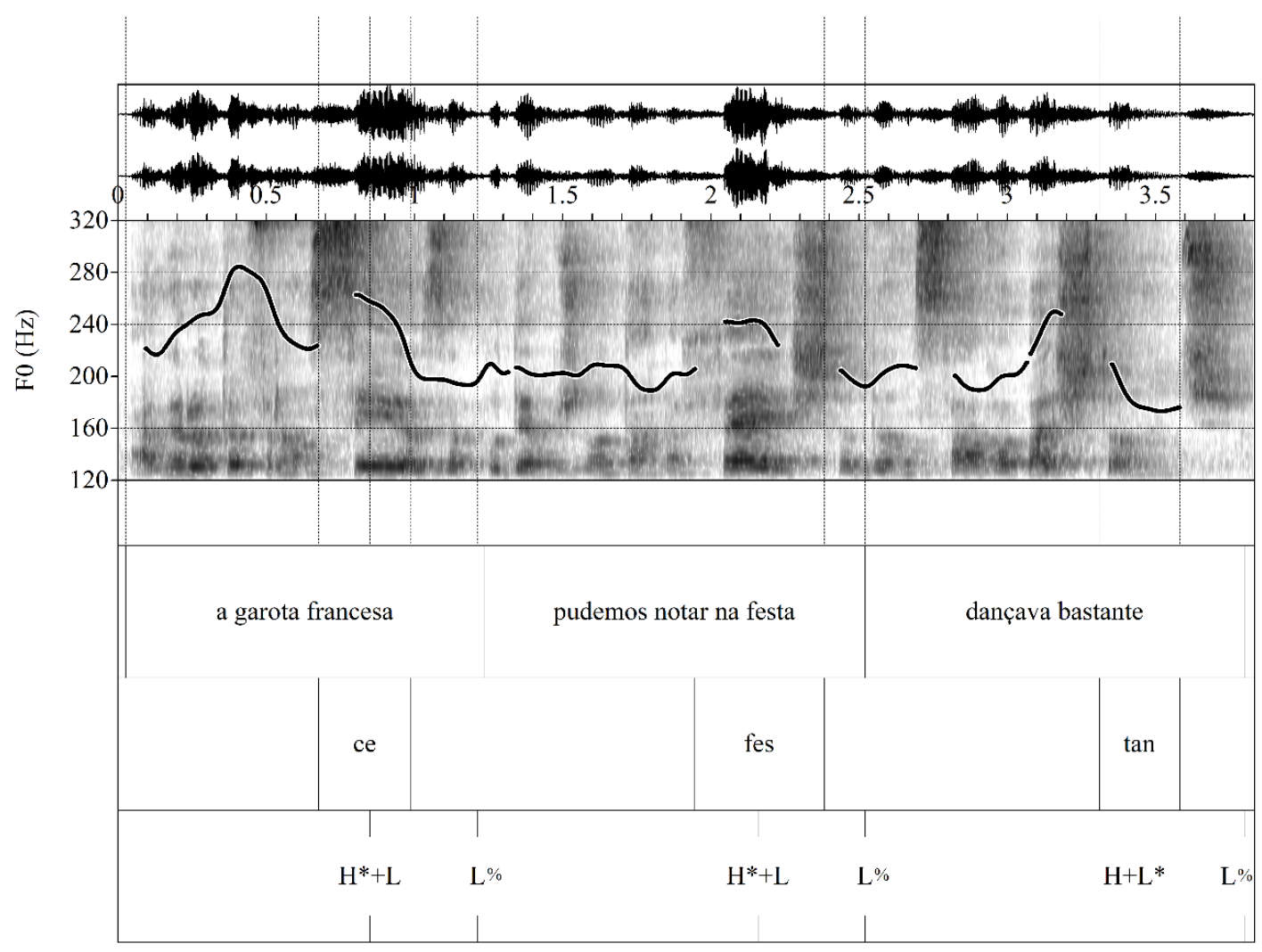

Fonte: As autoras (2018).

Figura 5. Enunciado 06B, informante KX

[Os alunos de cinco anos $]_{I P}$ [a velha professora assegura $]_{I P}$ [conhecem o alfabeto $]_{I P}$

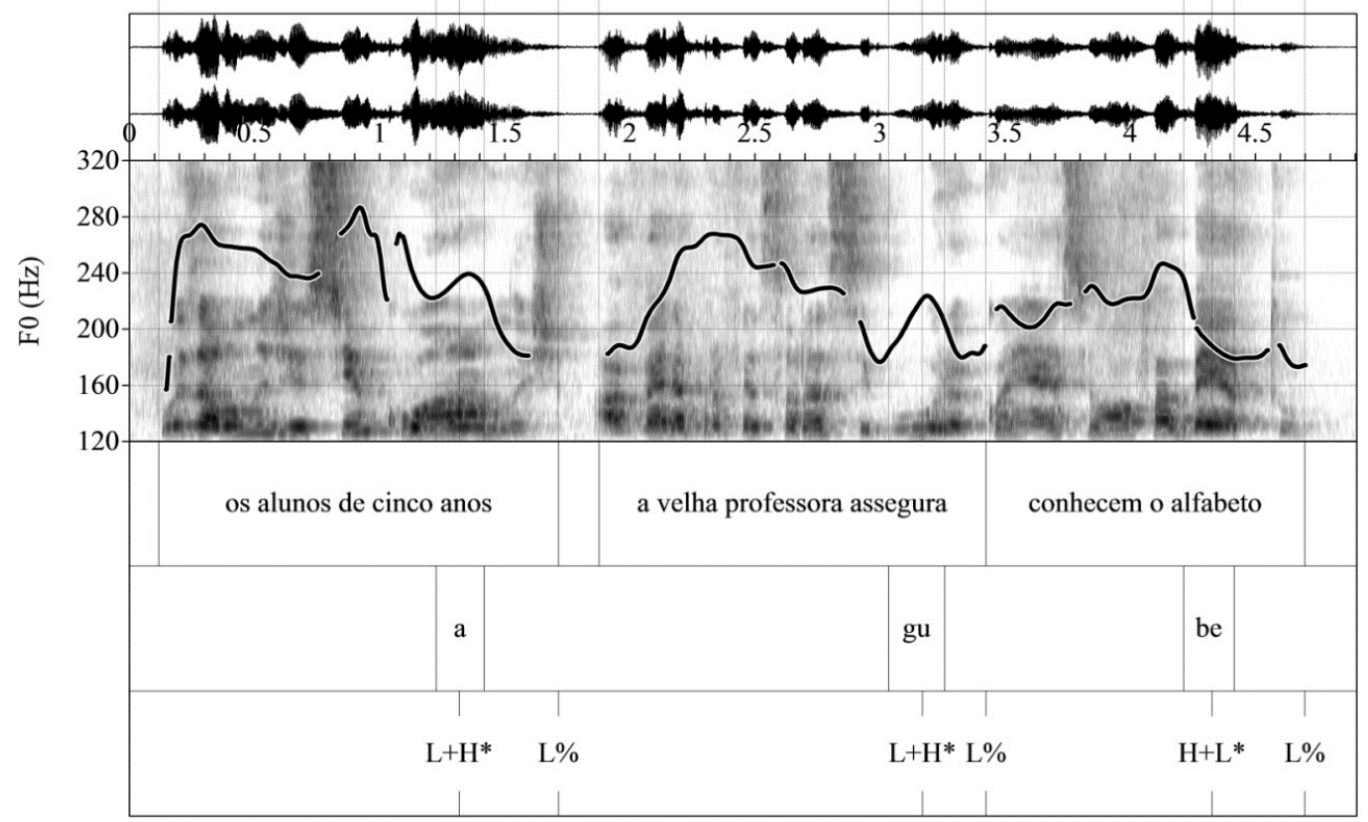

Fonte: As autoras (2018). 
É válido observar, no entanto, que há tendências individuais marcadas: três das quinze informantes contrariam a tendência geral e apresentam predomínio de tons de fronteira altos e movimentos ascendentes (cf. Figura 6).

Figura 6. Enunciado 02C, informante HT [A dupla de jovens imigrantes peruanos $]_{I P}[\text { você sabe disso }]_{I P}\left[\right.$ procura trabalho ${ }_{I P}$

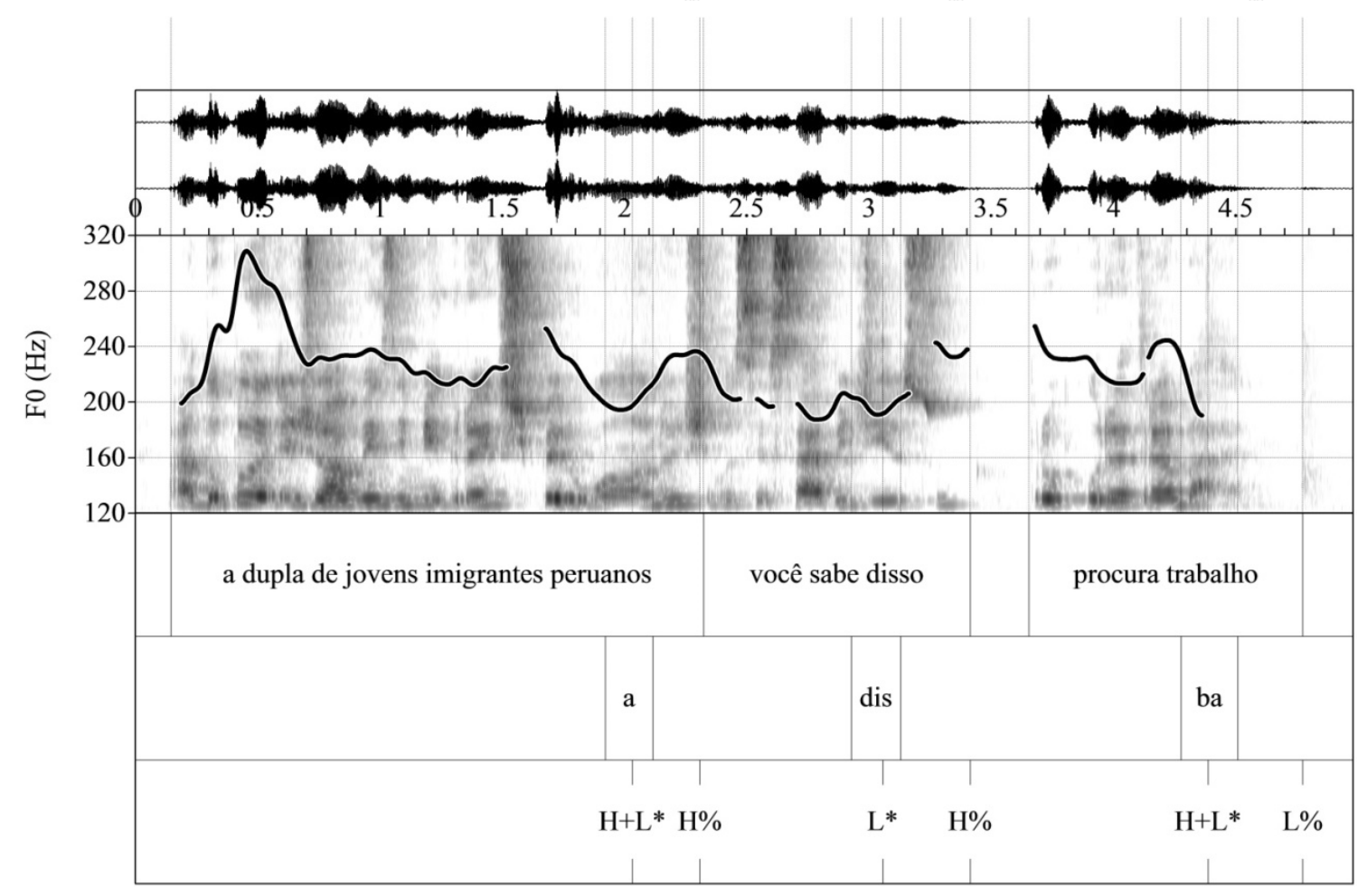

Fonte: As autoras (2018).

Ao que parece, não há relação entre o tipo de parentética (i.e., tipo de estrutura sintática / relação semântica entre o conteúdo da parentética e a hospedeira) e a ocorrência de tom de fronteira alto ou baixo. Na realidade, os resultados da distribuição de tons altos e baixos foram extremamente similares para as parentéticas do tipo 1 e do tipo 2 (cf. Tabela 4). 
Tabela 3. Distribuição de tons de fronteira altos e baixos no segundo IP por tipo de parentética, excluídos os dados sem tom de fronteira

\begin{tabular}{|l|c|c|c|c|}
\hline \multirow{2}{*}{ Tipo de parentética } & \multicolumn{2}{|c|}{ Tom Alto } & \multicolumn{2}{c|}{ Tom Baixo } \\
\cline { 2 - 5 } & oco. & \% & oco. & \% \\
\hline (1) Comentário & 197 & $34,2 \%$ & 212 & $65,8 \%$ \\
\hline (2) Aposto & 363 & $36 \%$ & 348 & $64 \%$ \\
\hline Total & 560 & $100 \%$ & 560 & $100 \%$ \\
\hline
\end{tabular}

Fonte: Elaborado pela autora.

É interessante notar que, nos dados analisados, houve maior ocorrência de contornos ascendentes e de tons de fronteira altos nos IPs aos quais não se sucede uma pausa silenciosa (cf. Tabelas 4 e 5). Sendo esses os movimentos melódicos típicos do contorno continuativo no português do Brasil (CUNHA, 2000; TENANI, 2002; SERRA, 2009, 2016; SILVESTRE, 2012), o falante parece dispensar a presença da pausa para indicar o fim (só) da unidade entoacional, que na verdade indica a continuidade do discurso.

Tabela 4. Contorno nuclear do primeiro IP versus ocorrência de pausa após o primeiro IP

\begin{tabular}{|l|c|c|c|c|c|}
\hline \multicolumn{1}{|c|}{ Contorno 1o IP } & Sem pausa & \% sem pausa & Com pausa & \%com pausa & Total geral \\
\hline Ascendente $^{*}$ & 83 & $22,5 \%$ & 31 & $15,7 \%$ & 92 \\
\hline Circunflexo & 113 & $30,5 \%$ & 57 & $28,9 \%$ & 137 \\
\hline Descendente & 91 & $24,5 \%$ & 86 & $43,4 \%$ & 142 \\
\hline Plano alto * & 2 & $0,7 \%$ & 2 & $1,3 \%$ & 4 \\
\hline Plano baixo & 9 & $2,4 \%$ & 7 & $3,8 \%$ & 13 \\
\hline Desc.-Asc. ${ }^{*}$ & 63 & $17,1 \%$ & 14 & $6,9 \%$ & 62 \\
\hline N/A & 9 & $2,4 \%$ & - & - & 7 \\
\hline Total geral & 370 & $100 \%$ & 198 & $100 \%$ & 568 \\
\hline
\end{tabular}

Legenda: $\left(^{*}\right)$ - contornos com tom de fronteira alto

Fonte: As autoras (2018).

Ainda na Tabela 4, verifica-se a maior ocorrência de contornos ascendentes, no primeiro IP, nos dados em que não ocorre pausa (22,5\% contra $15,7 \%)$ e, se juntarmos os dados dos três tipos de contornos que contam com tons de fronteira altos (ascendente, plano alto e descendente-ascendente), verificamos que os tons $\mathrm{H} \%$ totalizam 40,3\% dos 
dados com pausa, e apenas $23,9 \%$ dos dados sem pausa, no que se refere ao primeiro IP. O teste estatístico Chi Quadrado revelou evidências de associação entre essas variáveis, com p-valor $=0.000049$.

Na Tabela 5, verifica-se o mesmo em relação ao segundo IP. Somando-se os contornos com tom $\mathrm{H} \%$, temos um contraste ainda maior: $50,7 \%$ de tons altos nos dados sem pausa contra $31,7 \%$ de tons altos nos dados com pausa. Como dissemos, esse resultado pode se dever ao fato de que os contornos ascendentes, no português, estão tipicamente associados a um padrão melódico continuativo, enquanto os contornos descendentes estão associados às assertivas/declarativas neutras. Novamente, o teste Chi Quadrado revelou significância estatística da associação entre as variáveis, com p-valor $=0.015319$.

Tabela 5. Contorno nuclear do segundo IP versus ocorrência de pausa após o segundo IP

\begin{tabular}{|l|c|c|c|c|c|}
\hline \multicolumn{1}{|c|}{ Contorno 2o IP } & Sem pausa & \%sem pausa & Com pausa & \%com pausa & Total geral \\
\hline Ascendente * & 86 & $24,9 \%$ & 44 & $19,4 \%$ & 104 \\
\hline Circunflexo & 91 & $26,4 \%$ & 72 & $32,2 \%$ & 131 \\
\hline Descendente & 93 & $27,1 \%$ & 72 & $32,2 \%$ & 133 \\
\hline Plano alto $^{*}$ & 6 & $1,8 \%$ & 4 & $1,7 \%$ & 8 \\
\hline Plano baixo & 11 & $3,3 \%$ & 9 & $3,9 \%$ & 16 \\
\hline Desc.-Asc. ${ }^{*}$ & 50 & $14,4 \%$ & 24 & $10,6 \%$ & 59 \\
\hline N/A & 7 & $2,2 \%$ & - & - & 6 \\
\hline Total geral & 344 & $100 \%$ & 224 & $100 \%$ & 598 \\
\hline
\end{tabular}

\section{Legenda: $\left(^{*}\right)$ - contornos com tom de fronteira alto}

Fonte: As autoras (2018).

Os resultados com base na análise dos contornos melódicos confirmam a hipótese inicial de que as parentéticas constituem um sintagma entoacional (IP) independente, pelo menos na fala lida e considerando as variáveis aqui testadas. Além disso, levando em conta a pista acústica da pausa, o fraseamento prosódico mostrou-se sensível ao tamanho do primeiro IP: o total de ocorrências de pausas e suas durações aumentaram progressivamente nos dados, conforme o acréscimo do número de $\mathrm{Pw}$ no primeiro IP. Não foi possível, porém, observar qualquer relação entre o tamanho do primeiro IP e os tipos de acentos nucleares. Também não verificamos qualquer relação entre o tipo de estrutura interna da parentética (oracional $x$ não oracional) e o seu fraseamento prosódico. 
No que se refere então à relação entre a função textual-discursiva da parentética, sua característica sintática (ser um constituinte gerado fora da oração matriz) e sua realização prosódica, parece ser confirmada a intuição dos autores em geral no sentido de considerá-la

uma entidade linguística que é linearmente integrada em outra estrutura linguística, mas não é relacionada ao material linguístico circundante de uma forma ou de outra, i. e., em termos de estrutura sintática, significado semântico e/ou entoação (DEHÉ, 2014, p. 1).

Um fato importante a ressaltar é o de que a caracterização prosódica das parentéticas no PB, de acordo com nossos dados, difere daquela já descrita na literatura para o PE - tanto em relação às pausas quanto em relação à descrição tonal. Confirma-se, portanto, a tendência à diferenciação entre as gramáticas entoacionais dessas duas variedades do português, também em termos de fraseamento prosódico.

\section{Considerações finais e propostas para o aprofundamento da pesquisa}

Vislumbrando um aprofundamento da pesquisa sobre a prosódia das estruturas parentéticas no $\mathrm{PB}$, podemos propor outras análises de dados desse mesmo tipo de estrutura: no que concerne à verificação de pistas acústicas, um estudo que leve em conta a velocidade de fala e o alongamento silábico no fraseamento das parentéticas pode trazer resultados interessantes - tais pistas, no entanto, não foram analisadas neste artigo, pois isso exigiria a elaboração de uma nova amostra de fala, com maior controle do conteúdo segmental. Também seria interessante realizar testes de percepção com ouvintes naïves, pois, mesmo quando não se identificam tom de fronteira ou pausa, parece haver ruptura prosódica. Por fim, em etapa posterior, seria desejável realizar a análise de dados de fala espontânea e comparação com os resultados para fala controlada.

\section{Referências}

BARBOSA, Plínio; MADUREIRA, Sandra. Manual de fonética acústica experimental: aplicações a dados do português. São Paulo: Cortez, 2015.

BARROS, Nádia. Fraseamento prosódico em Português: uma análise entoacional de enunciados com parentéticas e tópicos em duas variedades do Português Europeu. Dissertação de Mestrado em Linguística. Lisboa: Universidade de Lisboa, 2014.

BECKMAN, Mary E.; Pierrehumbert, Janet B. Intonational Structure in Japanese and English. Phonology Yearbook III. 1986. p. 15-70. 
BOERSMA, Paul; Weenink, David. Praat: doing phonetics by computer. Versão 6.0.06. Disponível em: www.praat.org .

BURTON-ROBERTS, Noel. Parentheticals. In: BROWN, E. K. (Ed.). Encyclopaedia of Language and Linguistics. Elsevier Science, 2006. p. 179-182

CALDAS, Vitor Gabriel. "Aî" sequenciador na fala espontânea: fraseamento prosódico e entoação no português brasileiro. Dissertação de Mestrado. UFRJ/FL, 2018.

CHOMSKY, Noam; HALLE, Morris. The sound pattern of English. New York: Harper and Row, 1968.

CRUZ, Marisa. Prosodic variation in European Portuguese: phrasing, intonation and rhythm in central-southern varieties. Tese de doutoramento. Lisboa: UL, 2013.

DEHÉ, Nicole. Parentheticals in spoken English: the syntax-prosody relation. New York: Cambridge University Press, 2014.

FERNANDES, Flaviane Romani. Ordem, focalização e preenchimento em português: sintaxe e prosódia. Tese de Doutorado em Linguística. Campinas: IEL/UNICAMP, 2007.

FERNANDES-SVARTMAN, Flaviane R. et al. Intonational phrasing across varieties of Portuguese. In: CRUZ, M.; OLIVEIRA, P.; FROTA, S. (Ed.) Prosodic variation (with) in languages: intonation, phrasing and segments. Equinox Publishing. No prelo.

FROTA, Sónia. Prosody and focus in European Portuguese. Phonological phrasing and intonation. New York: Garland Publishing, 2000.

.The intonational phonology of European Portuguese. In: JUN, S. (Ed.). Prosodic Tipology II. Oxford: Oxford University Press, 2014.

FROTA, Sónia; VIGÁRIO, Marina. Aspectos de prosódia comparada: ritmo e entoação no PE e no PB. In: CASTRO, R. V.; BARBOSA, P. (Ed.). Actas do XV Encontro Nacional da Associação Portuguesa de Lingüística, v.1. Coimbra: APL, 2000. p. 533-555.

FROTA, Sónia. et al. Melodia ou Texto? Estratégias de acomodação entre melodia e texto no Português. Diadorim: revista de estudos linguísticos e literários v. 17, n. 2. Rio de Janeiro: UFRJ, 2015. p.12-33.

FROTA, Sónia. et al. Intonational variation in Portuguese: European and Brazilian varieties. In: FROTA, S.; PRIETO, P. (Ed.). Intonation in Romance. Oxford: Oxford University Press, 2015, p. 235-283.

JUBRAN, Clélia Cândida A. S. et al. Organização Tópica da Conversação. 2. ed. In: ILARI, Rodolfo (Org.). Gramática do Português Falado. v. II. Campinas: Ed. da Unicamp, 1993. p. 69-82.

- Inserção: um fenômeno de descontinuidade na organização tópica. In: CASTILHO, Ataliba T. (Org.). Gramática do Português Falado. v. 3. Campinas: Editora da UNICAMP. 1996a, p. 61-74. 
. Para uma descrição textual-interativa das funções da parentetização. In: KATO, Mary A. (Org.). Gramática do português falado. v. V. Campinas: Editora da Unicamp / Fapesp, 1996b, p. 339-354.

- Funções textuais-interativas dos parênteses. In: MOURA NEVES, Maria Helena de (Org.). Gramática do português falado. v. VII. Campinas: Editora da Unicamp, 1999, p.131-158.

. Parênteses: propriedades identificadoras. In: CASTILHO, Ataliba Teixeira de \& BASÍLIO, Margarida (Org.). Gramática do português falado. V. IV. 2.ed. Campinas, Editora da Unicamp/Fapesp, 2002, p. 411-419.

. Parentetização. In: JUBRAN, Clélia Cândida A. S.; KOCK, Ingedore G. Villaça. Gramática do português culto falado no Brasil. v. I: Construção do texto falado. Campinas: Editora da Unicamp, 2006, p. 301-357.

LADD, D. Robert. Intonational phonology. 2. ed. Cambridge University Press, 2008.

MORAES, João Antonio. The pitch accents in Brazilian Portuguese: analysis by synthesis. Proceedings of Speech Prosody. Campinas: Brasil, 2008. p. 389-398.

MINCOFF, Luciane Braz Perez. Inserções parentéticas: mecanismos de interação social. Anais do CELSUL. UFRGS, 2008.

NESPOR, Marina; VOGEL, Irene. Prosodic phonology. Dordrecht: Foris, 1986.

Prosodic Phonology. 2. ed. Berlin/New York: Mouton de Gruyter, 2007.

PIERREHUMBERT, Janet. The phonology and phonetics of English intonation.PhD Thesis. Massachussets: MIT, 1980.

R CORE TEAM. R: A language and environment for statistical computing. R Foundation for Statistical Computing, Vienna, Austria, 2016. Disponível em: https:/ /www.R-project. org/.

SELKIRK, Elisabeth. Phonology and syntax: the relation between sound and structure. Cambridge: MIT Press, 1984.

On derived domains in sentence phonology. Phonology 3. MIT Press, 1986, p. 371-405.

SERRA, Carolina Ribeiro. Realização e percepção de fronteiras prosódicas no português do Brasil: fala espontânea e leitura. Tese de doutorado. Rio de Janeiro: UFRJ-FL, 2009.

. A interface prosódia-sintaxe e o fraseamento prosódico no português do Brasil. Joss Journal of Speech Science, v. 5, p. 47-86, 2016.

SILVESTRE, Aline Ponciano dos Santos. A entoação regional dos enunciados assertivos nos falares das capitais brasileiras. Dissertação de Mestrado. Rio de Janeiro: UFRJ/FL, 2012.

TENANI, Luciani Ester. Análise prosódica das inserções parentéticas no corpus do Projeto da Gramática do Português Falado. Dissertação de Mestrado. Campinas: Unicamp-IEL, 1995. 
. Domínios prosódicos no português do Brasil: implicações para a prosódia e para a aplicação de processos fonológicos. Tese de Doutorado. Campinas: Unicamp-IEL, 2002. VIGÁRIO, Marina. Prosodic structure between the Prosodic Word and the Phonological Phrase: recursive nodes or an independent domain? The Linguistic Review, v. 27, n. 4, 2010, p. 485-530.

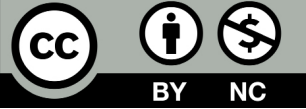

Data de submissão: 15/03/2018

Data de aceite: 07/06/2018 